\title{
0 rosto e a voz como inscrições do sofrimento em dois road movies
} The face and voice as suffering inscriptions in two road movies

\author{
Gustavo Souza $^{1}$
}

ㅁoutor em Ciências da Comunicação pela ECA/USP, mestre em Comunicação e Cultura pela ECO/UFRJ e graduado em Comunicação Social/Jornalismo pela UFPE. Professor do Programa de Pós-Graduação em Comunicação e Cultura Midiática da Universidade Paulista. E-mail: gustavo03@uol.com.br 
Resumo: The brown bunny (Vincent Gallo, 2003) e Viajo porque preciso, volto porque te amo (Marcelo Gomes e Karim Aïnouz, 2010) são dois filmes de estrada com muitos pontos em comum: o principal deles é o estado de espírito de seus protagonistas, Bud Clay e José Renato, que sofrem pelo término de seus relacionamentos afetivos. Diante disso, este trabalho discute o enquadramento dos road movies na seara dos gêneros cinematográficos, para, a seguir, debater como os filmes inscrevem na imagem e no som o estado emocional de seus personagens. A hipótese é de que os close-ups no rosto de Clay e os relatos orais de José Renato funcionam como catalisadores das emoções dos protagonistas nesses dois filmes.

Palavras-Chave: Filme de estrada; emoção; close-up; voz.

Abstract: The brown bunny (Vincent Gallo, 2003) and Viajo porque preciso, volto porque te amo (Marcelo Gomes e Karim Aïnouz, 2010) are road movies with many points in common: the main one is the mood of their central characters, Bud Clay and José Renato, both suffering due to the end of their affective relationships. Therefore, this paper discusses the framework of road movies the field of film genres. Also, a debate is developed about how movies materialize in image and sound the emotional state of their characters, especially the pain of an absence. The hypothesis adopted is that the close-ups on the face of Clay and oral reports of José Renato inscribe of the emotions of these protagonists.

Key words: Road movie; emotion; close-up; voice. 


\section{Introdução}

A câmera subjetiva mostra a estrada com carros à frente e, por vezes, totalmente vazia. Vê-se também o entorno: a vegetação, um descampado, uma casa isolada na paisagem. O que se ouve, praticamente, são músicas que abordam o término de um relacionamento afetivo, bem como a tristeza ou a angústia que segue o rompimento. Esta sequência pode ser vista tanto em The brown bunny (Vincent Gallo, 2003) como em Viajo porque preciso, volto porque te amo (Marcelo Gomes e Karim Aïnouz, 2010). Seus protagonistas são Bud Clay (Vincent Gallo) e José Renato (Irandhir Santos), respectivamente. Clay é piloto profissional do circuito de motos. Ele terminou de competir em New Hampshire e está em direção à próxima disputa na Califórnia. José Renato é um geólogo que saiu de Fortaleza rumo ao interior do Nordeste para mapear uma região onde futuramente haverá um canal.

Há muitos pontos comuns entre esses dois filmes: seus personagens centrais se deslocam na estrada em decorrência de suas atividades profissionais; sofrem com o fim de seus relacionamentos; ao longo do percurso, aproximam-se de outras mulheres, mas nem sempre essa tentativa é bem sucedida; lembram, mas também tentam esquecer suas companheiras; a trilha sonora remete a dores de amor.

Por meio desses dois filmes, este texto quer discutir as emoções no road movie, especialmente o sofrimento decorrente da perda. Para isso, o trabalho se divide em duas partes: primeiramente, discute alguns pressupostos relacionados ao filme de estrada ${ }^{2}$, tais como o seu enquadramento aos gêneros cinematográficos, bem como as razões do deslocamento dos personagens. O debate sobre o road movie como gênero se torna uma porta de entrada para outras searas, como, por exemplo, o estudo da composição do personagem, porém distanciado da tipificação cara a esse gênero. Por esse motivo, opto por abordagens que elegem inúmeras possibilidades do movimento nos filmes, incluindo, nessa discussão, os road movies (ELEFTHERIOTIS, 2012), assim como a experiência de dirigir em diversas frentes, sendo uma delas o cinema (BORDEN, 2013). Na segunda etapa, centro as atenções em dois aspectos fílmicos close-ups do rosto de Bud Clay e a voz da narração de José Renato - como catalizadores do estado emocional desses dois personagens. A hipótese adotada é que os closes no rosto, associados à música presente em muitos desses planos, e a voz, combinada com as imagens do espaço por onde ela circula, ajudam a compor os sentidos desses dois filmes em suas abordagens das emoções.

로se termo será utilizado como um sinônimo para road movie. 


\section{A falta que nos move ${ }^{3}$}

"O principal objetivo do cinema deve ser retratar as emoções" (MUNSTERBERG, 1983, p. 46).

"Há certas ideias que a esquerda - sobretudo a esquerda masculina - tem se mostrado tipicamente recatada para discutir. Isso inclui o amor, a morte, o mal, a fé, a ética, a tragédia, o não ser, a mortalidade, o sacrifício e o sofrimento" (EAGLETON, 2010, p. 316).

O diagnóstico de Munsterberg, publicado pela primeira vez em 1916, parece não ter encontrado um desenvolvimento posterior, não apenas na reflexão sobre cinema, mas também em outras áreas, de modo que Eagleton, quase cem anos depois, vem chamar a atenção para a ausência do debate sobre diversos "temas tabus" nas ciências humanas. Entre eles, estão algumas emoções como, por exemplo, o sofrimento. Porém, tal lacuna vem sendo aos poucos preenchida com estudos que tratam de inúmeras emoções no cinema (PLANTINGA, 1999; PODALSKY, 2011; DIDI-HUBERMAN, 2015). Como elas podem assumir as mais diversas materializações na matéria dos filmes, isso exige, de saída, um recorte. Aqui, pretendo me deter, conforme o "estado de espírito" dos personagens descrito na introdução, em uma única emoção: a dor da perda, que, já antecipando o que se verá adiante, será tomada como força motriz para as ações de Bud Clay e José Renato nas estradas que percorrem.

Em Viajo..., o acesso ao personagem José Renato se dá apenas por meio de sua voz. Seu rosto ou qualquer outra parte do seu corpo não são revelados. Os temas de suas falas podem ser divididos em três tópicos: trabalho, vida pessoal e comentários sobre pessoas que conhece ao longo da viagem. Ele descreve em detalhes os procedimentos de um geólogo, bem como a dificuldade em lidar com a separação de Joana, sua companheira. A viagem é de trabalho, mas serve também para fazer lembrar e tentar esquecer. Num dado momento, ele desabafa: “a única coisa que me faz feliz nessa viagem são as lembranças de ti. Não, galega, isso é mentira. Não sei escrever carta de amor, não aguento a ideia de ficar só. Sabia que a única coisa que me deixa triste nessa viagem são as lembranças de ti?". Mais à frente: "pela primeira vez fiquei 24 horas sem pensar no meu passado", diz José Renato, referindo-se ao período que passou com uma garota de programa chamada Paty. Se, em Viajo..., a voz de José Renato é o fio condutor da narrativa, em The brown bunny, praticamente não se ouve a voz de Clay. O foco, nesse filme, são as ações praticamente silenciosas

${ }^{3}$ Tomo de empréstimo o título de umas das peças dirigidas por Christiane Jatahy. 
do personagem, com uma frequência para close-ups em seu rosto. Retomarei, na segunda parte desse trabalho, a possível relação entre rosto e voz quando esses dois filmes são justapostos. Por ora, é válido frisar que os motivos da viagem desses dois personagens se distanciam daqueles comumente apontados pela literatura sobre o filme de estrada.

É comum a associação entre marginalidade e os personagens dos road movies. Autores como Corrigan (1991) ou Laderman (2002) analisam a produção norte-americana, especialmente das décadas de 1960 e 1970, para postular como característica central dos personagens desses filmes a recusa aos códigos de conduta socialmente desejáveis. Geralmente são assaltantes, assassinos ou golpistas, mas também pessoas que não se enquadram em normas sociais tradicionalmente instituídas. Em resumo, a condição central do personagem desse gênero cinematográfico é de ser outsider. A expansão da produção desse tipo de filme, bem como os debates subsequentes, revela que esse prisma, embora pioneiro e basilar, é hoje insuficiente para dar conta de filmes de estrada realizados inclusive nos Estados Unidos, como é o caso de The brown bunny. Por essa razão, é preciso filiar-se a perspectivas menos engessadas na abordagem de temas como deslocamento e viagem no cinema. Uma delas é a de Eleftheriotis (2012): para ele, exploração, descoberta e revelação formam a tríade necessária para a investigação do movimento no cinema, pois ela ativa "as especificidades históricas e culturais do registro emotivo" (ELEFTHERIOTIS, 2012, p. 70, grifo meu). Mais que aplicar esse modelo aos filmes em questão, interessa perceber como a apropriação dessa temática pode revelar (um dos aspectos que compõe o debate proposto pelo autor) os motivos do deslocamento dos personagens sem perder de vista as emoções.

Como descrito acima, o motivo central das viagens de Bud Clay e José Renato é o trabalho, cujo andamento, porém, estará diretamente atrelado à dimensão existencial de ambos. Desde o início, José Renato lida com a viagem em contagem regressiva, na medida em que o peso da ausência se torna mais angustiante, esse sentimento reverbera no trabalho, causando dispersões e atrasos no cronograma. Já Bud Clay cria situações que sempre remetem à sua namorada, Daisy (Chloë Sevigny), como visitar a casa em que moraram ou ir a uma loja de animais para saber o tempo médio de vida de um coelho, já que seu último presente para ela fora um coelho de chocolate por ocasião da páscoa. Adiante, a narrativa mostrará que tais situações são "ficções" para tornar suportável a dor da ausência. Assim, no vai e vem entre o pessoal e o profissional, entre o público e o particular, esses momentos revelam que a angústia da falta se reverte no impulso necessário para seguir viagem. Não se trata mais 
de quebrar códigos de conduta ou seguir numa vivência errante. Filmes de estrada como os abordados aqui acenam, portanto, para a ampliação dos modos de ver seus personagens. A questão não se resume em defender a falta como o motivo central que move os personagens nos road movies, mas tomá-la como uma possível chave de leitura que transcende as determinações do gênero. E mais importante: o que gera essa falta? Para onde ela conduz os personagens? Tal questionamento encaminha a discussão para o seguinte tópico: tendo em vista a diversidade de fatores que fazem os personagens dos road movies se deslocarem, o fato de a narrativa se desenrolar na estrada é suficiente para considerá-lo um gênero? Quando comparado a outros gêneros - western, terror ou comédia romântica -, em que não se vê grandes alterações das ações e do destino dos personagens, o filme de estrada apresenta uma diversidade quase imensurável em relação aos motivos da viagem. Não pretendo defender que o road movie não seja um gênero, mas apenas compartilhar uma inquietação a respeito desse formato que, certamente, merecerá mais atenção em outro momento. Por agora, é preciso voltar aos filmes.

Embora haja vários pontos comuns entre ambos, o sofrimento dos personagens, entretanto, é causado por razões diferentes: como dito antes, José Renato foi deixado por sua companheira, já Bud Clay sofre porque Daisy morreu engasgada com o próprio vômito após o uso de drogas e álcool em uma festa. Porém, isso só é revelado no final do filme e, até chegar a esse ponto, a narrativa dá a entender que ela está viva e que os dois estão separados por uma razão desconhecida. A lembrança de Daisy perturba Clay constantemente no trajeto que faz, especialmente quando relembra momentos de alegria e de leveza. No meio do caminho, assim como José Renato, ele também tenta se relacionar com outras mulheres, mas sem sucesso. A tentativa comum a esses dois personagens mostra que a dor da falta exige movimento. É a falta que move, para retomar o título acima, pois, como pontua Didi-Huberman (2015), emoção é movimento, cujo caminho vai em direção a instâncias particulares e públicas, isto é, emoções são sentidas pelo corpo, mas construídas e compartilhadas na coletividade, já que é na tentativa (ainda que fracassada) de superar a angústia da falta que José Renato e Bud Clay se esforçam para interagir com o entorno, seja para lembrar ou para esquecer.

No caso de The brown bunny, com a morte como acontecimento significativo para o destino do personagem, ganha importância o papel da memória. O modo como o filme convoca essa relação entre morte e memória contrapõe duas instâncias: a situação narrativa e as opções escolhidas para o desenrolar da história. Em outras palavras, todo o filme se ancora em indícios de realidade bastante verossímeis até o 
momento em que Clay tem uma espécie de sonho (ou delírio) com Daisy. Trata-se de uma prestação de contas entre os dois, quando ele a questiona porque abusou do álcool e das drogas a ponto de ficar inconsciente e ter sido estuprada por três homens. Desse modo, The brown bunny materializa em imagem e som a conversa que ele gostaria de ter tido com Daisy, mas que, devido às circunstâncias, tornou-se impossível. Essa sequência aciona a reflexão de Bakhtin sobre a formação e a importância da memória na atividade estética: "depois do enterro, depois do monumento tumular vem a memória. Tenho toda a vida do outro fora de mim, e aí começa a construção estetizante de sua personalidade, sua consolidação e seu acabamento numa imagem esteticamente significativa” (BAKHTIN, 2003, p. 97-98, itálicos do autor). Tal construção busca na lembrança momentos considerados relevantes, cujo alicerce é composto por forças distintas, porém complementares: quando associado ao impacto das emoções, o verossímil gera uma estetização do outro que pode facilmente ir além dos índices de realidade. Diante da dor da perda, o personagem produz descontinuidades na narrativa que desestabiliza, inclusive, o nosso acesso à elaboração estética de suas emoções. Para isso pouco importa se a situação é inverossímil, pois ela tem valor na medida em que expressa seu estado emocional. Em resumo, a dor da ausência ultrapassa a fidelidade à realidade para elaborar a peça que falta na "construção estetizante" da imagem que Bud Clay tem a respeito de Daisy, ou seja, o movimento da memória pode elaborar situações inimagináveis para que assim o conflito entre os dois personagens se resolva.

Em outra sequência, José Renato diz: "Em casa ela é botânica e eu, geólogo. Um estuda as falhas nas rochas e o outro, flores. Um escava a terra e tira pedras, enquanto o outro colhe flores. Um casamento perfeito, todo casamento é perfeito, até que acaba”. Nesse relato, vê-se também a busca pelas lembranças já comentadas, mas diferentemente de The brown bunny, que materializa na imagem as lembranças positivas que Bud tem com Daisy, em Viajo... só é possível acessar o real estado do personagem por meio de seu tom voz que, de acordo com Bakhtin (2003), é uma instância imprescindível para a análise de qualquer enunciado oral. É pelo tom de voz que o personagem manifesta suas impressões, angústias e desejos, tornando-se a mais concreta dimensão do seu estado emocional. Enquanto em The brown bunny esse trabalho de memória ganha corpo na imagem, em Viajo... ganha na voz, mas ambos permitem uma aproximação entre as perspectivas de Bakhtin e Didi-Huberman, em que uma afirmação desse último autor reforça a do primeiro: “emoção é um movimento fora de si: ao mesmo tempo em mim (mas é uma coisa tão profunda que escapa à minha razão) e fora de mim (e é uma coisa que me atravessa totalmente para 
me escapar de novo)" (DIDI-HUBERMAN, 2015, p. 29). Na tentativa de lidar com o passado, em The brown bunny e Viajo porque preciso, volto porque te amo percebe-se que esse movimento simultâneo de dentro e de fora apresenta como resultado a insistência na dor, ainda que involuntariamente, seja por meio dos relatos de José Renato ou das lembranças de Clay, para, quem sabe assim, se aventar um novo começo. Trata-se, portanto, de utilizar a falta como um motor que gera movimento, a fim de aprender a conviver com a ausência ou, simplesmente, de aprender a perder a fim de se livrar da dor que os consome.

Bud Clay e José Renato têm, portanto, no trabalho o propósito de suas viagens. Entretanto, a dor da falta estabelece um considerável desnível entre os aspectos profissional e pessoal de ambos. Enquanto o primeiro transcorre sem muitos empecilhos, especialmente no início da jornada de José Renato ${ }^{4}$, o segundo é atravessado por uma espécie de deriva comum aos personagens dos "filmes de excursão" (CORRIGAN, 2015, p. 112), ou seja, filmes de excurso, de deambulação, em que prevalece o movimento no espaço com um sujeito viajante alterado ou desestabilizado. Se anteriormente, apoiado em Eleftheriotis, propus verificar o que esses personagens em movimento revelam, agora, com base na discussão de Corrigan sobre o filme-ensaio em sua versão de viagem, pode-se afirmar que a desorientação constitui um aspecto também relevante de tais personagens. Embora haja um objetivo (mapear a região por onde o canal passará ou chegar à próxima cidade onde ocorrerá a competição), "há uma percepção confusa da possibilidade de expressar ideias e um desejo de estar em outro lugar que não aquele onde estão" (CORRIGAN, 2015, p. 116). Essa apropriação, contudo, não é literal, pois não entrarei no mérito da existência (ou não) da dimensão ensaística desses filmes. Porém, as características apontadas podem ultrapassar o filme-ensaio, sendo válidas também para a análise de outros filmes de estrada.

\section{Rosto e música, voz e imagem}

"Eu só quero que você se encontre. Ter saudade até que é bom, é melhor que caminhar vazio, a esperança é um dom que eu tenho em mim." (Sonhos, Peninha, 1977)

"When you hold me tight, how could life be anything, but beatiful, I think that I was made for you and you were made for me." (Beautiful, Gordon Lightfoot, 1972)

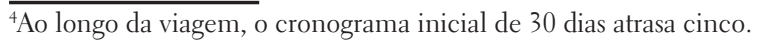


O estado emocional de Bud Clay o leva a inúmeras tentativas de exorcizar a dor que sente. Em uma dessas, o personagem revela o tipo de relação que estabelece com o seu automóvel. Ao longo da viagem, ele para num deserto de sal, retira a moto que está na traseira e a pilota até sua imagem se diluir na paisagem. A combinação entre o cansaço físico e o emocional força uma pausa a fim de escapar, ainda que temporariamente. Querer perder-se é uma possibilidade, mas voltar à estrada é uma obrigação. Essa passagem conduz ao debate sobre o papel e a importância do carro nos filmes de estrada. Em muitos casos, ele é diretamente associado à aventura, à liberdade, ao risco e ao prazer. Nesses dois filmes, entretanto, o status do carro muda: deixa de ser "um objeto absolutamente mágico" - como disse Barthes (2007, p. 152) em sua análise do novo Citroën - para se tornar lugar de solidão, das lembranças que trazem sofrimento e das tentativas fracassadas de aproximação com outras mulheres. Das três que Bud Clay encontra no caminho, duas chegam a entrar no carro, mas ficam por poucos minutos, pois logo ele desiste delas. Nenhum dos dois personagens usa o veículo como uma contrapartida para benefícios ou conquistas; ao contrário, o furgão de Bud e a caminhonete de José Renato são espaços com outras funções: encontros rápidos, escritório, casa; mas também, em seus fluxos temporários, lugar de interação com o exterior, distração e monotonia em que ambos, talvez por estarem sozinhos, não deixam de externar a dor da falta pelo choro (Bud Clay) ou por relatos angustiados (José Renato).

Essa diversidade de usos para o veículo - também distante do que tradicionalmente se vê nos road movies norte-americanos - aciona o conceito de "automobilidade" (FEATHERSTONE, 2014), ou seja, uma junção das noções de autonomia e mobilidade que serve para pensar a experiência de dirigir na estrada, mas também a interação com o exterior, em que a função do carro não se restringe a percorrer lugares selvagens, desertos ou remotos, mas também à "capacidade de ir a qualquer lugar, para se locomover e habitar sem pedir permissão, uma vida auto-dirigida livre da vigilância das autoridades" (FEATHERSTONE, 2014, p. 2). Assim, tal conceito se torna relevante também por ultrapassar as delimitações e expectativas em torno do road movie como gênero.

Sem perder de vista o foco desse trabalho - as emoções, em especial a dor da perda -, apoio-me em perspectivas que pensam a automobilidade também em sua dimensão emotiva. Na discussão sobre o ato de dirigir, Sheller (2004) desloca o enfoque das questões técnicas, econômicas ou ambientais para as emocionais. Segundo a autora, tal dimensão tem sido negligenciada, mas para esse trabalho ela se torna particularmente importante especialmente quando se corrobora a ideia de que: "o consu- 
mo de um carro não se limita a escolhas racionais, pois tem muito a ver com questões estéticas, emocionais e sensoriais (...). Podemos perguntar como sentimentos por, de e com carros geram sensibilidades que são social e culturalmente incorporadas em práticas familiares e sociais do uso do carro, circulações e deslocamentos realizados por carros, estradas e motoristas" (SHELLER, 2004, p. 222). Na esteira do conceito de automobilidade encontra-se também o trabalho de Borden (2013), cujo interesse pelo cinema é central. Ele acredita que, devido à sua natureza imagética, o cinema é o meio de expressão que melhor fornece a sensação de dirigir e que as subjetividades do espaço, construídas pelo cinema, expressam inúmeras dimensões culturais que se distanciam de tentativas homogêneas sobre o ato de dirigir (BORDEN, 2013, p. 12-15). Dos motivos que apresenta para a inclusão de filmes nesse debate, o que mais interessa reter é aquele que considera a experiência de dirigir como percepção, projeção, representação e engajamento, sempre vinculados a aspectos culturais e subjetivos. Semelhante a Sheller, ele não desconsidera a importância dos aspectos econômicos, tecnológicos, urbanísticos ou ambientais, porém se mostra mais interessado em "refletir sobre diversos tipos de emoção" (BORDEN, 2013, p. 11) invocados pela experiência de dirigir quando retratada pelo cinema.

A discussão sobre automobilidade pressupõe também o espaço para além do carro, por interferir no estado emocional de quem o dirige. Porém, nos filmes aqui debatidos, a relação com o entorno está mais explícita em Viajo... Quando não comenta sobre o fim do relacionamento com Joana ou sobre o trabalho, José Renato fala a respeito das pessoas que conhece durante a viagem: artesãos, romeiros, moradores de vilarejos isolados, prostitutas, pedintes, um casal de namorados, pescadores. Num tom que flerta com o documental, o personagem descreve e, em alguns casos, elabora algumas interpretações a respeito dessas pessoas. A caminhonete que dirige sequer aparece ao longo do filme ou é por ele citada como algo significativo. Em The brown bunny, nas pausas durante a viagem, vê-se Bud Clay em busca por Daisy de diversas formas: numa loja de animais, na casa onde moraram, na interação com outras mulheres. Desse modo, pode-se afirmar que, embora o automóvel seja o meio responsável pelo deslocamento dos personagens -Viajo..., em maior grau, e The brown bunny, em menor intensidade - constroem uma automobilidade que majoritariamente parte do veículo em direção ao exterior rumo a pessoas, objetos e paisagens.

Adiante, voltarei a essa relação com entorno. Por ora, é preciso questionar o seguinte: se o carro assume uma posição secundária na construção da automobilidade nesses dois filmes, em quais elementos o estado emocional dos personagens estará 
mais latente? A hipótese adotada é que a questão se transfere, não exclusivamente, mas recorrentemente, para os planos em close-up do rosto de Bud Clay e para o relato oral de José Renato. Dito de outro modo: rosto e voz materializam mais diretamente as emoções de ambos. Transfere-se, assim, a atenção da máquina para o sujeito.

Embora ambos tenham que lidar com a dor da perda, há diferenças no modo como os filmes apresentam essa dimensão existencial: à verborragia de José Renato, contrapõe-se o silêncio excessivo de Clay que beira à incomunicabilidade. Enquanto dirige, a imagem que se vê de Bud Clay é basicamente um close-up à direita do seu rosto. Nesses planos, ele está sempre em silêncio, o cabelo balança com o vento e, por vezes, chora. Essa opção imagética estabelece mais facilmente, num primeiro momento, o estado emocional do personagem, bem como facilita a criação de um pacto de intimidade com o espectador cujo acesso ao sofrimento dos personagens se dá mais facilmente. É válido lembrar que os enquadramentos desses planos não se alteram, não há zoom in ou zoom out em relação ao rosto filmado.

Dialogando com o trabalho de Béla Balázs, um dos primeiros teóricos do cinema a pensar o close-up, Aumont (1998) defende que, quando um primeiro plano expõe um rosto sobre toda a superfície da imagem, esse rosto encarna o todo da ação dramática proposta pela narrativa. Com o personagem em silêncio, o close no rosto se torna uma zona nebulosa que orienta parcialmente o espectador sobre o seu estado emocional. Ao longo do filme, vê-se o seu sofrimento, mas a causa que provoca o choro, por exemplo, está em suspenso. Poderia ser de saudade, mas também de arrependimento por não ter interferido no momento em que Daisy estava sendo estuprada, como também de raiva da própria Daisy, por ter exagerado no consumo de álcool e drogas. Em suma, o recorte ampliado do rosto não permite o acesso aos reais motivos de tal comoção e abre a possibilidade para ambiguidades, corroborando o que disse Balázs: “a expressão facial é a manifestação mais subjetiva do homem, mais subjetiva até mesmo que a fala (...), não governada por cânones objetivos" (1983, p. 93), ou seja, o rosto em close é mais polifônico que a própria linguagem. Desse modo, se a memória possibilita uma construção estetizada do outro, como ressaltou Bakhtin, tal construção também encontra ancoragem no rosto em close-up, pois boca, olhos e lágrimas, por exemplo, compõem múltiplas expressões de memórias e emoções que talvez as palavras não consigam captar. Aqui, seguindo o percurso de Aumont, o rosto funciona como uma superfície em que se desenha uma subjetividade e se extraem interpretações e significados. Porém esse recorte, em The brown bunny, buscará na música um meio para explicitar a subjetividade do personagem.

Nesses close-ups, há geralmente uma música extradiegética cuja letra reflete 
o estado emocional de Clay: Milk and honey, de Jackson C. Frank, e Beautiful, de Gordon Lightfoot, tratam de solidão, de separação e da dor da ausência. Quando "falam” pelo personagem, mesmo que imprimam "a sua participação na emoção da cena" (CHION, 2011, p. 14), sendo, portanto, “empáticas", essas músicas estabelecem também diferentes níveis de intensidades: da zona ambígua que pode ser o close-up do rosto passa-se a uma seara mais nítida. Porém, o close não apenas isola uma parte do corpo, mas intensifica, com a ajuda da música, a percepção do processo dramático-narrativo por parte do espectador, ainda que parcialmente. Essa lacuna, no entanto, é relevante porque, se dirigir no cinema é projeção e engajamento (BORDEN, 2013), tem-se uma trajetória indeterminada e incompleta, uma mobilidade (ou automobilidade, para usar o conceito acima descrito) que revela emoções por meio de um rosto que sofre e cuja importância está mais para as polifonias decorrentes da junção entre imagem e música que para um acesso transparente aos motivos do sofrimento do personagem. Isso não implica, contudo, estabelecer hierarquias entre imagem e palavra, mas reconhecê-las como instâncias que, quando interligadas, produzem uma infinidade de sentidos.

Se em The brown bunny, o close-up do rosto de Bud Clay materializa o estado emocional do personagem, em Viajo..., o foco se desloca para a voz de José Renato. Voz da narração tal qual um diário que expõe um sujeito à deriva, como se ouve, num dado momento: "Manhã do dia 52 da nossa separação, eu sinto que sobrevivi a um terremoto. Seis semanas longe de casa são seis gotas como de um calmante poderoso, um calmante que não resolve a dor, mas tranquiliza o juízo”. Como dito antes, suas falas remetem a três temas: trabalho, vida pessoal e comentários sobre as pessoas com quem encontra durante a viagem. Na medida em que a narrativa avança, agrava-se a angústia e a desorientação, de modo que José Renato embaralha esses universos e experiências, tornando esses três pontos praticamente uma unidade. Embora a voz da narração remeta constantemente ao término do relacionamento e à posterior crise por que passa o personagem, ela não revela as causas do rompimento. Sabe-se, no máximo, que Joana tomou a iniciativa para deixá-lo, mas o motivo permanece oculto. Aqui, como os close-ups no rosto de Bud Clay, a voz de José Renato também funciona como uma instância lacunar e ambígua.

Na relação circular que se estabelece entre os três tópicos acima, a ausência de uma justificativa para o fim da relação cede lugar para que se acompanhe a narração de seu sofrimento sem amarras quanto à exposição de si: sua voz fala do tormento das lembranças; da dificuldade em lidar com a solidão; das tentativas bem sucedidas, mas também fracassadas de aproximação com outras mulheres (por exemplo, ele 
parece não se incomodar em dizer que "brochou" com uma garota de programa) e da possibilidade de aventar um novo futuro sem Joana. A força retórica de sua narração maneja a voz como um meio que especula e questiona valores, cujo sentido está mais para o compartilhamento de experiências do que para a preocupação com possíveis julgamentos morais. Dito isso, saber o motivo da separação se torna menos importante. Desloca-se a atenção da causa para o acompanhamento de uma vivência marcada pela dor da ausência e pelo sofrimento subsequente.

Ressaltei anteriormente, com a ajuda de Bakhtin, a importância do tom de voz para a avaliação dos enunciados orais - uma dimensão importante, sem dúvida, mas se restringir a ela conduz a uma análise textualista, sendo necessário considerar o espaço por onde essa voz circula, até porque a natureza do cinema é antes de tudo imagética. Evidentemente, não é possível remeter a todos os momentos em que se dá a articulação entre voz e espaço, pois isso implicaria uma análise de quase todo o filme. É nas sequências em que aborda o rompimento com Joana que se nota mais disjunções entre o que se ouve e que se vê. Dentre esses momentos, destaco uma sequência em que José Renato narra os "amores e ódios" que sente e o quanto as lembranças tornam a viagem e o trabalho ainda mais difíceis. Durante essa narração, o que se vê é a montagem de uma feira livre até o momento em que o espaço estará tomado por pessoas. Dois motivos talvez ajudem a explicar essa opção: se a imagem do protagonista não aparece, Joana também “apareceria” apenas em sua narração; mas pode ser também o reaproveitamento de imagens feitas anteriormente pelos diretores para o documentário Sertão de acrílico azul piscina (Marcelo Gomes e Karim Aïnouz, 2004), cujo mote inicial foi as feiras de cidades do Nordeste e que posteriormente teria em Viajo... uma espécie de continuação5.

Especulações à parte, aqui a narrativa estabelece um esquema circular entre o imagético e o discursivo, ou seja, as imagens que mostram o início de um processo até a sua efervescência seguem um relato que evidencia o contrário. Do início para o apogeu, do apogeu para o fim. Se nesse filme a voz é a expressão mais direta das emoções do personagem, essas imagens podem ser vistas, então, como um reflexo do desejo de José Renato (ou da construção estetizada do outro, para retomar Bakhtin), isto é, voltar ao início e assim começar tudo outra vez. Afinal, emoções, estados de espírito e pensamentos não são, em si mesmos, pertinentes ao espaço, mesmo que sejam visualizados através de meios que os representem. Prevalece, novamente, o caráter circular antes sinalizado, que só encontrará um desvio na última sequência do filme, quando José Renato se mostra disposto a "mergulhar para a vida, num mer-

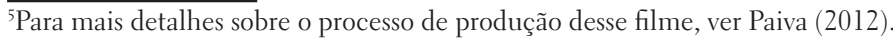


gulho cheio de coragem", e as imagens mostram homens que saltam de penhascos em direção ao mar. A música que se ouve no primeiro plano do filme - Sonhos, de Peninha - fala de rejeição, mas também de superação e resignação ("mas não tem revolta, não, eu só quero que você se encontre..."). Nota-se a circularidade entre palavra (no início) e a imagem (no fim), só que agora não mais para insistir na dor da ausência, mas para vislumbrar um novo começo, dessa vez, sem Joana.

\section{Considerações finais}

Emoção, movimento e tentativa em lidar, mas também superar a dor compõem a arquitetura das ações dos personagens centrais dos dois filmes debatidos neste trabalho. Com Bud Clay e José Renato, vê-se que a dor da ausência gera sofrimento que, por sua vez, exige uma tomada de decisão para superar a angústia ou vivenciá-la até o esgotamento. Filmes como The brown bunny e Viajo porque preciso, volto porque te amo permitem a relativização dos cânones da literatura sobre o filme de estrada, especialmente aqueles realizados fora dos Estados Unidos, pois um grupo de filmes com características que refletem um contexto cultural específico não pode ser tomado como a pedra angular da discussão sobre o filme de estrada. Nessa direção, em vez de adotar perspectivas prévias, este texto partiu dos filmes a fim de verificar os caminhos que os road movies apontam. Mais que seguir uma "cartilha”, importa perceber os desvios que os filmes estrada apresentam frente a considerações canônicas. Em vez de se deslocar a esmo ou em decorrência de uma fuga da lei, desloca-se devido ao trabalho, desloca-se para tentar esquecer, desloca-se para fazer da ausência o motor das intenções e das ações dos personagens.

É preciso investigar também como os filmes resolvem essa questão na imagem e no som. Nesse caso, a discussão se torna mais pontual, exigindo uma investigação mais direcionada sobre cada filme que apresentará perspectivas distintas ou exclusivas. Os dois filmes aqui em foco recorrem ao close-up no rosto e às potencialidades da voz para, assim, materializar as emoções de seus personagens. O primeiro caso, The brown bunny, revela as ambiguidades e polifonias do rosto em primeiro plano, mas torna esses mesmos planos lugares de acesso à memória, que, no cinema, pode transcender a oralidade para se tornar imagem - algo já ressaltado por André Bazin e que é útil retomar: "a memória é o mais fiel dos filmes, o único que podemos impressionar em qualquer altitude e até a hora da morte" (1991, p. 41). Por outro lado, se é certo que no cinema, depois da invenção da banda sonora, é pouco provável que haja uma imagem dissociada de sonoridade, a voz será o recurso que Viajo 
porque preciso, volto porque te amo tomará como central para fornecer o acesso à história e às vivências de seu protagonista. Uma voz da narração que é circular mas, ao mesmo tempo, exterior ao espaço por onde circula e interior, na medida em que expõe, nos relatos sobre pessoas, lugares e experiências, a sua interiorização.

\section{Referências}

AUMONT, J. El rostro en el cine. Barcelona; Buenos Aires: Paidós, 1998.

BAKHTIN, M. Estética da criação verbal. 3. ed. São Paulo: Martins Fontes, 2003.

BALÁZS, B. “A face do homem”. In: XAVIER, Ismail (org.). A experiência do cinema. Rio de Janeiro: Graal, 1983.

BARTHES, R. Mitologias. 3. ed. Rio de Janeiro: Difel, 2007.

BAZIN, A. O cinema: ensaios. São Paulo: Brasiliense, 1991.

BORDEN, I. Drive: journeys through film, cities and landscapes. Londres: Reaktion Books, 2013.

CHION, M. A audiovisão: som e imagem no cinema. Lisboa: Texto e Grafia, 2011.

CORRIGAN, T. Cinema without walls: movies and culture after Vietnam. New Brunswick: Rutgers University Press, 1991.

2015.

O filme-ensaio. Desde Montaigne e depois de Marker. São Paulo: Papirus,

DIDI-HUBERMAN, G. Que emoção! Que emoção? Lisboa: KKYM, 2015.

EAGLETON, T; BEAUMONT, M. A tarefa do crítico: diálogos com Terry Eagleton. São Paulo: Editora Unesp, 2010.

ELEFTHERIOTIS, D. Cinematic journeys: film and moviment. Edinburgh: Edinburgh University Press, 2012.

FEATHERSTONE, M. “Automobilities: an introduction”. Theory, Culture 6 Society. Londres, vol. 21, n. 4-5, p. 1-24, 2004.

LADERMAN, D. Driving visions: exploring road movie. Austin: University of Texas Press, 2002.

MUNSTENBERG, H. “As emoções”. In: XAVIER, Ismail (org.). A experiência do cinema. Rio de Janeiro: Graal, 1983.

PAIVA, S. "Roteiros abertos em filmes de busca”. XXXV Congresso Brasileiro de Ciências da Comunicação, 2012, Fortaleza. Anais eletrônicos. Disponível em http:// www.intercom.org.br/papers/nacionais/2012/resumos/R7-2489-1.pdf. Acesso em 10 de dezembro de 2015. 
PLANTINGA, C; SMITH, G. M. (orgs). Passionate views: film, cognition, and emotion. Baltimore: The Johns Hopkins University Press, 1999.

PODALSKY, L. The politics of affect and emotion in contemporary latin american cinema: Argentina, Brasil, Cuba, and Mexico. Nova York: Palgrave Macmillan, 2011.

SHELLER, Mimi. “Automotive emotions: feeling the car”. Theory, Culture \& Society. Londres, vol. 21, n. 4-5, p. 221-242, 2004.

\section{Referências audiovisuais}

SERTÃO de acrílico azul piscina. Marcelo Gomes e Karim Aïnouz, Brasil, 2004.

THE BROWN bunny. Vincent Gallo, Estados Unidos, 2003.

VIAJO porque preciso, volto porque te amo. Marcelo Gomes e Karim Aïnouz, Brasil, 2010. 